\title{
Práticas de Discussão em Sala de Aula de Matemática: os casos de dois professores
}

\author{
Discussion practices in the mathematics classroom: the cases of two \\ teachers
}

\author{
Cátia Rodrigues* \\ ORCID iD 0000-0002-2504-5032 \\ Luís Menezes $^{* *}$ \\ ORCID iD 0000-0002-8978-8900 \\ João Pedro da Ponte ${ }^{* * *}$ \\ ORCID iD 0000-0001-6203-7616
}

\begin{abstract}
Resumo
As discussões matemáticas constituem uma forma poderosa para promover a aprendizagem dos alunos ao favorecerem a apresentação, justificação, argumentação e sistematização dos raciocínios associados ao trabalho com tarefas matemáticas. O professor desempenha um papel preponderante na condução da discussão, sendo chamado a realizar um conjunto de ações de ensino, tendo por base o seu conhecimento didático. Neste artigo apresentamos as práticas de discussão de dois professores de Matemática do $8 .^{\circ}$ ano de escolaridade, com o objetivo de compreender como conduzem discussões em tópicos de Álgebra. O estudo é qualitativo interpretativo e baseia-se no estudo de caso de dois professores, que integram um grupo colaborativo. Os resultados mostram que os professores estruturam a discussão matemática em três momentos principais e gerem o discurso com vista à generalização de ideias algébricas. Para isso, empreendem um conjunto de ações de ensino que favorecem a apresentação, justificação e argumentação de diversas estratégias de resolução.
\end{abstract}

Palavras-chave: Práticas de Discussão. Matemática. Conhecimento Didático.

\begin{abstract}
Mathematical discussions are a powerful activity for students' learning by supporting the presentation, justification, argumentation, and systematization of the reasoning associated to the work on mathematical tasks. The teacher plays a fundamental role in leading the discussion, being called to carry out a set of instructional actions, based on his/her didactic knowledge. In this paper, we present discussions practices of two $8^{\text {th }}$ grade mathematics teachers, in order to understand how they use discussions when teaching algebra topics. The study is qualitative and interpretive and is based on the case study of two teachers, who are part of a collaborative group. The results show that the teachers structure the mathematical discussion at three main moments and manage the

\footnotetext{
* Doutoranda em Didática da Matemática pelo Instituto de Educação da Universidade de Lisboa, IE. Professora na Escola Básica e Secundária de Sever do Vouga, Sever do Vouga, Portugal. Endereço para correspondência: Rua do Sobreiral, Sever do Vouga, CEP: 3740-232. E-mail: catiamat@gmail.com.

** Doutor em Educação, Especialidade de Didática da Matemática, pela Universidade de Lisboa, Portugal. Professor Adjunto na Escola Superior de Educação do Instituto Politécnico de Viseu e CI\&DETS. Endereço para correspondência: Rua Maximiano Aragão, Viseu, Portugal, CEP: 3504-501. E-mail: menezes@esev.ipv.pt.

*** Doutor em Educação Matemática pela Universidade da Georgia, EUA. Professor catedrático da Universidade de Lisboa, Instituto de Educação, Lisboa, Portugal. Endereço para correspondência: Alameda da Universidade, Lisboa, CEP: 1649-013. E-mal: jpponte@ ie.ulisboa.pt.
} 
discourse for the generalization of algebraic ideas. Thereby, they undertake a set of instructional actions that help the presentation, justification, and argumentation of several solution strategies.

Keywords/Palabras clave: Discussions Practices. Mathematics. Didactic Knowledge.

\section{Introdução}

As discussões são momentos de trabalho na sala de aula com grandes potencialidades para a aprendizagem dos alunos, ao favorecerem o seu envolvimento na apresentação, justificação, argumentação e negociação de significados para os seus raciocínios quando trabalham com tarefas matematicamente significativas (PONTE; MATA-PEREIRA; QUARESMA, 2013; SHERIN, 2002; STEIN et al., 2008). Particularmente no trabalho com tarefas que envolvem ideias algébricas, as discussões podem promover o desenvolvimento da capacidade de generalização e de simbolização, caraterísticas marcantes do trabalho dos alunos com a Álgebra no 3..$^{\circ}$ ciclo do Ensino Básico (EB). O professor desempenha um papel fundamental na promoção deste tipo de discussões e, para realizar com sucesso esta prática, desenvolve um conjunto de ações complexas (CENGIZ; KLINE; GRANT, 2011; PONTE; MATA-PEREIRA; QUARESMA, 2013) que são apoiadas no seu conhecimento didático (PONTE, 2011). Este conhecimento é multidimensional e convoca diferentes domínios da prática letiva, da Matemática, do currículo, dos alunos e da aprendizagem. Neste artigo apresentamos as práticas de discussão matemática de dois professores de Matemática do 3. ${ }^{\circ}$ ciclo do EB, com vista a compreender como conduzem discussões matemáticas coletivas, a partir do trabalho dos alunos com tarefas algébricas, apoiados no seu conhecimento didático.

\section{Práticas de discussão matemática e conhecimento didático}

A condução de discussões que têm como objetivo levar o aluno a envolver-se na apresentação, justificação, argumentação e negociação de significados resultante do seu trabalho com tarefas matemáticas é uma prática complexa do professor. Neste sentido, Stein et al. (2008) apresentam o modelo das cinco práticas - antecipar, monitorizar, selecionar, sequenciar e estabelecer conexões entre as respostas dos alunos - como uma ferramenta para apoiar os professores no desempenho dessa atividade.

Na prática de antecipar, que decorre no momento da planificação da aula, o professor pensa em possíveis resoluções que os alunos podem realizar da tarefa, em possíveis dificuldades que podem enfrentar e formas de as ultrapassar e como pode levá-los a atingir o objetivo 
definido para a aula. Na monitorizar, já em sala de aula, o professor acompanha o trabalho dos alunos, prestando atenção às suas estratégias de resolução, em particular aos conceitos mobilizados, representações usadas, dificuldades e erros cometidos. Esse acompanhamento contribui para a prática seguinte, em que seleciona as estratégias que têm potencial para serem apresentadas e comentadas em coletivo, evitando repetições e garantindo a discussão de ideias importantes. Na quarta prática, sequenciar, o professor organiza as intervenções dos alunos face às estratégias de resolução escolhidas, de modo a atingir os objetivos delineados para a aula. Por fim, no estabelecimento de conexões, dá início à apresentação e justificação das estratégias selecionadas e sequenciadas, procurando que os alunos relacionem raciocínios e argumentem sobre os dos colegas.

Focalizando ainda mais a discussão coletiva que ocorre na aula, Sherin (2002) identifica os seguintes momentos principais: apresentação de ideias; comparação e avaliação; e filtragem, que se repetem até à conclusão da discussão. No primeiro momento, os alunos são convidados a apresentar e justificar as suas estratégias de resolução das tarefas propostas. $\mathrm{O}$ professor pode optar por iniciar pelas incorretas, se considerar pertinente analisar o erro cometido, pelas mais frequentes, de forma a envolver mais alunos na discussão, por se identificarem com a estratégia em análise, ou pelas de fácil compreensão, por permitirem um claro acompanhamento dos raciocínios desenvolvidos (STEIN et al., 2008).

No segundo momento, os alunos são chamados a analisar e relacionar os raciocínios presentes nas diversas estratégias, comparando resoluções próximas e distantes. No último momento, são desafiados a pensar sobre um raciocínio particular que foi partilhado ou introduzido pelo professor, com vista a ampliar as suas ideias iniciais. Durante a condução, o discurso gerado sofre um afunilamento de ideias seguido de ampliação, já que tem início com o professor a solicitar e discutir muitas ideias, para depois focar a atenção dos alunos em algumas particulares que desencadeiam uma nova solicitação e discussão de mais contributos, e assim sucessivamente. O conteúdo desse discurso segue um processo de estreitamento, já que inicialmente o professor, como pretende ter muitas ideias em análise, não se preocupa muito com o seu conteúdo para, em seguida, focar a atenção dos alunos em ideias específicas que contribuem para atingir o propósito da discussão.

O professor desempenha, durante a condução da discussão, um conjunto de ações de ensino que, para Cengiz, Kline e Grant (2011), são de três tipos: as de elicitar que pressupõem convidar os alunos a partilhar as suas estratégias; as de apoiar que permitem recordar o objetivo da discussão ou do problema, sugerir a interpretação de um raciocínio, repetir um argumento, reforçar o pensamento do aluno e introduzir diferentes representações e contextos; e as de 
ampliar que levam os alunos a avaliarem um argumento ou observação, a oferecerem um raciocínio para um argumento, a compararem diferentes estratégias, a usarem a mesma estratégia em novos problemas e a apresentarem argumentos.

Apoiados neste referencial teórico, Ponte, Mata-Pereira e Quaresma (2013) propõem um outro quadro que procura clarificar a natureza destas ações: as ações de convidar, que introduzem o aluno na discussão; as ações de apoiar/guiar que promovem a sua continuidade na discussão; as ações de informar/sugerir, que permitem apresentar informação e argumentos ou validar respostas; e as ações de desafiar, que levam o aluno a introduzir representações, interpretar e estabelecer conexões, a raciocinar, a argumentar e a avaliar. Os quadros teóricos apresentados para descrever as ações de discussão têm algumas caraterísticas em comum: iniciam com o convite aos alunos para apresentação das suas estratégias de resolução, continuam com a promoção do seu envolvimento na discussão com o objetivo de os levar a transitar da apresentação para a justificação e relacionamento de ideias.

Para o desempenho das práticas de discussão o professor precisa apoiar-se no seu conhecimento. Para Shulman (1986), este conhecimento organiza-se em três grandes categorias: conhecimento do conteúdo, conhecimento pedagógico do conteúdo e conhecimento do currículo. O primeiro agrega o conhecimento de conceitos e procedimentos a mobilizar; o segundo implica conhecer diferentes formas de representação, exemplos, explicações, demonstrações e das dificuldades que os alunos podem enfrentar na aprendizagem de dado assunto e respectivas causas e estratégias para as ultrapassar. O terceiro inclui o conhecimento de programas e materiais curriculares. Shulman (1987) acrescenta quatro novas categorias ao seu modelo, defendendo que é importante que o professor conheça dinâmicas de sala de aula e o contexto educativo onde vai decorrer o ensino.

A partir dos trabalhos de Shulman (1986; 1987), Ball, Thames e Phelps (2008) introduzem novos domínios de conhecimento, com o objetivo de clarificar os conceitos e o alcance de cada um, dedicando um interesse especial ao conhecimento pedagógico do conteúdo. Para estes autores, o conhecimento matemático para ensinar inclui quatro domínios principais: conhecimento comum do conteúdo, que diz respeito ao conhecimento que os professores necessitam para conhecer conceitos e notações, para saber quando os alunos dão uma resposta errada, ou para apreciar quando os materiais curriculares apresentam uma definição incorreta; conhecimento especializado do conteúdo, que é o conhecimento necessário para compreender os erros dos alunos e para avaliar se uma abordagem diferente das mais usuais se pode aplicar em qualquer contexto, para interpretar conceitos de diversas formas, para definir trajetórias de aprendizagem de um conceito; conhecimento do conteúdo e dos alunos que pressupõe que o 
professor seja capaz de antecipar dificuldades e raciocínios dos alunos na realização de certa tarefa; e conhecimento do conteúdo e do ensino, que está relacionado com o conhecimento necessário para definir exemplos a apresentar, representações a usar, questões a colocar, justificações a solicitar e conduzir discussões matemáticas. Ball, Thames e Phelps (2008) reconhecem algumas fragilidades ao seu modelo relacionadas com o carácter estático que pode estar associado às suas categorias e à dificuldade em perceber o alcance de cada uma delas.

Ponte (2011) procura resolver o problema da segmentação e falta de dinâmica do modelo anterior, adotando uma perspectiva integradora das diversas vertentes do conhecimento do professor, em vez de o apresentar em categorias. Esse modelo, designado por conhecimento didático (Figura 1), tem no centro o conhecimento da prática letiva por ser aquele "onde se faz sentir de modo mais forte a especificidade da disciplina de Matemática” (p. 4).

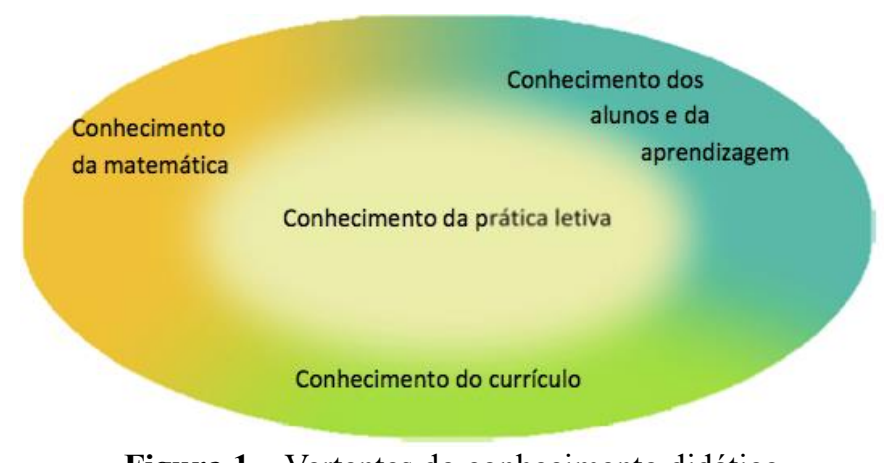

Figura 1 - Vertentes do conhecimento didático Fonte: Ponte, 2011, p. 4.

O modelo inclui, para além do conhecimento da prática letiva, os conhecimentos da Matemática, dos alunos e da aprendizagem e do currículo. O conhecimento da Matemática é entendido como a compreensão que o professor tem da Matemática enquanto disciplina escolar, no qual desempenham um papel importante os conceitos, os procedimentos, as representações e as conexões. O conhecimento dos alunos e da aprendizagem prevê que o docente conheça bem os seus alunos e as suas formas de pensar para promover uma boa aprendizagem. $\mathrm{O}$ conhecimento do currículo pressupõe, da parte do professor, o domínio dos documentos oficiais que orientam o seu trabalho, nomeadamente o programa de Matemática, já que lhe permite estruturar o seu ensino e justificar opções tomadas. O conhecimento da prática letiva inclui a elaboração de tarefas a propor aos alunos, a escolha do modo de trabalho mais adequado a cada tarefa e a promoção da comunicação matemática.

\section{Metodologia de investigação}

Este estudo pretende compreender práticas de discussão matemática de professores do 
EB, inserindo-se, assim, no paradigma interpretativo (ERICKSON, 1986), já que se quer interpretar as ações dos professores, e segue uma abordagem qualitativa, porque se valorizam processos didáticos em ambiente naturalístico (BOGDAN; BIKLEN, 1994). Optamos pela modalidade de estudo de caso, uma vez que pretendíamos estudar dois professores (com percursos profissionais bastante distintos) a lecionar Matemática ao $8 .^{\circ}$ ano de escolaridade, no mesmo agrupamento de escolas, incidindo, assim, numa identidade bem definida que tem como objetivo conhecer detalhadamente a realidade do seu ponto de vista, enfatizando-se o "como" e o "porquê" (PONTE, 2006), ou seja, compreender as suas práticas de discussão matemática. A escolha dos professores baseou-se no facto de lecionarem o $8 .^{\circ}$ ano de escolaridade e manifestarem interesse em participar no estudo.

A recolha de dados apoia-se em dois processos principais: observação participante de uma aula de cada professor e das sessões de trabalho colaborativo (SC), mencionadas mais à frente, das quais resulta a elaboração de um relatório individual (RI) por cada professor e entrevistas semiestruturadas (uma no início (EI) e outra no fim do estudo (EF)). As entrevistas têm a particularidade de "recolher dados descritivos na linguagem do próprio sujeito" (BOGDAN; BIKLEN, 1994, p. 34), em duas fases distintas do estudo.

A primeira teve como objetivo conhecer aspectos da vida profissional dos professores e as suas concepções e práticas relativas à condução de discussões coletivas, que contribuíram para a definição dos casos do estudo. A entrevista final pretendeu recolher a visão global dos professores sobre o trabalho desenvolvido. A observação participante permitiu aceder a outro tipo de informação distinta da disponibilizada pelas entrevistas, já que os professores foram observados na sua atuação em sala de aula, favorecendo uma melhor compreensão da sua atividade letiva. Os dados foram recolhidos através de gravações de áudio e vídeo, nas entrevistas, e na aula observada de cada professor. A investigadora (a primeira autora) é uma observadora participante, já que trabalha em conjunto com os professores no apoio individual prestado aos alunos no decorrer da aula observada.

A análise de dados recorreu à técnica de análise de conteúdo e definição de categorias de codificação. A análise de conteúdo teve início com as transcrições das entrevistas e das gravações da aula observada (sempre que nas transcrições das aulas não é possível identificar o aluno que fala, usamos somente a referência Aluno). Seguidamente, os dados foram percorridos, à luz do quadro teórico construído, com vista à identificação de regularidades que conduziram ao estabelecimento de categorias. Após o seu estabelecimento foi feita uma primeira tentativa de organizar os dados nas respectivas categorias, de modo a verificar a sua viabilidade, procedendo-se a ajustes que incluíram o abandono e/ou a definição de novas 
categorias, até se obter as categorias apresentadas no Quadro 1, assumidas como concretizações do tema estabelecido para a dimensão de análise do estudo: condução da discussão.

\begin{tabular}{cll}
\hline \multicolumn{1}{c}{ Dimensão } & \multicolumn{1}{c}{ Temas } & Categorias definidas \\
\hline & $\begin{array}{l}\text { Componentes da discussão, } \\
\text { processo e conteúdo do } \\
\text { discurso }\end{array}$ & $\begin{array}{l}\text { Apresentação; comparação, avaliação } \\
\text { e filtragem; conclusão }\end{array}$ \\
Condução da discussão & $\begin{array}{l}\text { Solicitação e discussão de muitas } \\
\text { ideias; filtragem; solicitação e } \\
\text { discussão de muitas ideias }{ }^{1}\end{array}$ \\
& $\begin{array}{l}\text { Conteúdo matemático não filtrado; } \\
\text { conteúdo matemático filtrado }\end{array}$ \\
\hline & Ações de ensino & Elicitar; Apoiar; Informar; Desafiar \\
\hline Quadro 1 - Dimensões, Temas e Categorias de análise \\
Fonte: Dados da pesquisa (2014).
\end{tabular}

A definição das categorias de análise foi inspirada nos quadros teóricos de Ponte (2011), Ponte, Mata-Pereira e Quaresma (2013) e Sherin (2002). As categorias foram aplicadas transversalmente às práticas de discussão de cada professor, em estreita articulação com o seu conhecimento didático. Focando as ações de ensino, a análise preliminar de dados indicou que, para caraterizar as ações empreendidas pelos professores, eram adequadas as categorias ações de elicitar, apoiar, informar e desafiar, o que constitui uma adaptação das categorias propostas inicialmente por Ponte, Mata-Pereira e Quaresma (2013). Nas componentes da discussão, fezse um reajustamento do quadro de Sherin (2002) agrupando as duas últimas componentes numa só e incluindo uma terceira designada, neste estudo, de conclusão. No que respeita à análise do conhecimento didático, segue-se o quadro teórico de Ponte (2011) por salientar o todo na relação entre as diversas vertentes, currículo, alunos e aprendizagem, prática letiva e Matemática.

O dispositivo de estudo é o trabalho colaborativo com três professores. Dois destes professores são os casos deste estudo e integram o grupo colaborativo, por se revelar uma estratégia poderosa de desenvolvimento profissional, fundamentalmente, como uma forma de concretizar mudanças curriculares (HARGREAVES, 1998). Neste sentido, o trabalho colaborativo constitui-se como o contexto favorável à realização deste estudo, possibilitando estudar os professores de modo a compreender as suas práticas de discussão, ao longo de um período alargado de tempo (um ano), em que as discussões são usadas como ferramentas promotoras da aprendizagem dos alunos. Assente nestes pressupostos, a organização do trabalho colaborativo partiu do interesse da investigadora que, para a constituição do grupo, apresentou a proposta a todos os professores de Matemática do agrupamento, enquadrada num

\footnotetext{
${ }^{1}$ A repetição desta categoria pretende mostrar o caráter cíclico do discurso que se gera durante a discussão coletiva.
} 
modelo de formação contínua. Surgiu, assim, a ação de formação sobre as discussões matemáticas no tema da Álgebra: Projeto Práticas de Discussão Matemática no Ensino da Álgebra (PPDMEA), organizada em dez sessões de trabalho presencial (com a duração aproximada de três horas cada), com o objetivo de criar dinâmicas de trabalho colaborativo e desenvolver práticas de discussão matemática e que ocorreu com a participação de quinze professores.

O trabalho realizado nas diversas sessões envolveu, globalmente, a reflexão sobre textos e episódios de sala de aula relacionados com as discussões matemáticas e com o tema da Álgebra, a partir das próprias experiências dos professores e a preparação de momentos de discussão coletiva para tarefas escolhidas pelos professores, de acordo com o modelo das cinco práticas de Stein et al. (2008). Em particular, na quarta sessão, os professores preparam tarefas para explorar em sala de aula as equações com denominadores, recuperando a tarefa Eleição do delegado de turma explorada na primeira sessão. Nesse sentido, o grupo fez pequenas adaptações à tarefa de forma a responder aos seus propósitos. A tarefa proposta aos alunos (Figura 2) apela a um contexto próximo das suas vivências e promove a tradução de informação apresentada em linguagem natural para linguagem matemática. A preparação prévia da aula com os professores contempla a antecipação de possíveis estratégias de resolução a serem apresentadas pelos alunos, de dificuldades que possam surgir e formas de as ultrapassar e um possível encadeamento para a apresentação das estratégias em sala de aula, em função das previstas pelos professores.

\begin{tabular}{|c} 
Tarefa 1 - "Eleição do delegado de turma" \\
A diretora de turma coordenou o processo de eleição do delegado de turma e informou no final que: \\
$\checkmark \quad$ Os 30 alunos da turma votaram e não houve votos brancos ou nulos; \\
$\checkmark \quad$ Apenas três alunos receberam votos: a Francisca, o Lucas e a Sandra; \\
$\checkmark \quad$ A Sandra recebeu mais cinco votos que a Francisca; \\
$\checkmark \quad$ O Lucas recebeu metade dos votos que recebeu a Sandra. \\
Quem ganhou as eleições? Com quantos votos? \\
Não te esqueças de apresentar e explicar o teu processo de resolução.
\end{tabular}

Figura 2 - Tarefa Eleição do delegado de turma Fonte: Dados da pesquisa (2013).

\section{$4 \mathrm{O}$ caso de Jorge}

\subsection{O professor}

Jorge é um professor que, no momento do estudo, tinha 30 anos de serviço. É formador na especialidade de tecnologias na sala de aula. Apesar da sua vasta experiência, continua a apostar na sua formação através da participação em projetos curriculares e de investigação. Vê 
no PPDMEA uma oportunidade de desenvolver um tipo de trabalho diferente com os seus alunos e que tem descurado, atualmente, um pouco: "Neste momento fazemos muito menos em termos de sala de aula, (...) de projetos, de trabalhos de grupo, de umas atividades mais de investigação com os miúdos" (EI, setembro de 2013). Reconhece, também, que o envolvimento no PPDMEA lhe permite partilhar experiências com colegas e desenvolver um trabalho mais sólido e metódico que ocorre na presença da investigadora:

Obrigam-nos a procurar, (...) a discutir e eu acho que estes momentos que tivemos (...) de preparação, (...) foram muito importantes e as ideias acabam por surgir, (...) sobretudo maneiras de pensar diferentes (...), o confronto de ideias

(EF, junho 2014).

Salienta também a oportunidade de aprofundar um tema matemático tão importante como a Álgebra e que levanta dificuldades aos alunos, principalmente a simbolização e a generalização: "Eles percebem o conceito, mas depois a parte formal (...) quando têm que formalizar aquilo numa expressão, torna-se um bocadinho dificil" (EI, setembro de 2013). Com o trabalho no PPDMEA, o professor trabalha colaborativamente produzindo materiais para a sala de aula que favoreçam as discussões matemáticas.

\subsection{A condução da discussão}

$\mathrm{Na}$ aula, Jorge recorre às ações de elicitar para iniciar a discussão coletiva com o convite à apresentação das estratégias de resolução que envolvem a utilização de linguagem matemática menos formal. Dirige o convite a um grupo de alunos para apresentação de uma resolução diferente das demais e menos poderosa algebricamente, por se basear num texto, acompanhado de cálculos numéricos que satisfazem as condições da tarefa (Figura 3). Esse convite é acompanhado da indicação clara do que pretende que o grupo de alunos apresente à turma e do pedido de explicações para os raciocínios desenvolvidos.

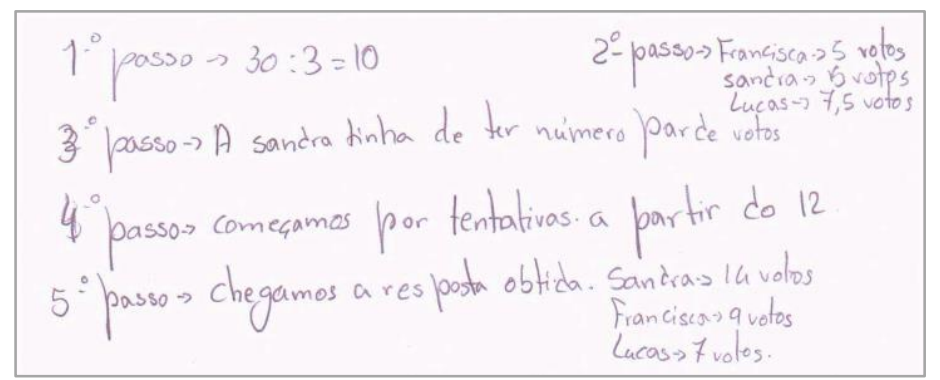

Figura 3 - Estratégia de resolução baseada na produção de um texto matemático Fonte: Dados da pesquisa (2014).

Assim que a resolução é exposta no quadro, o professor recorre às ações de desafiar 
para levar os alunos a analisarem o segundo passo da resposta, dando indicação da existência de um raciocínio errado e incentivando a procura de uma justificação para o erro:

Professor (P): Quero que passes exatamente esses passos que tens aí. Depois explicas mais ou menos como é que pensaram. (...) Vocês começaram pelo 10, foi? Eu acho que há ali uma coisa que não está muito bem naquele segundo passo. Por que é que aquele segundo passo está mal? [L.5] Mafalda: Então porque não há meios votos.

P: A conclusão está correta, a conclusão está correta, mas esse segundo passo não está muito correto, o segundo passo em si. A terceira está correta.

Aluno: Não podemos ter 7 votos e meio.

$P$ : Exatamente.

(Aula Equações, janeiro de 2014).

Embora a aluna apresente uma justificação válida (L.5), o professor continua a recorrer às ações de desafiar para reforçar a ideia da existência de um erro no segundo passo da resolução (L.6-7), de modo a levá-los a procurarem outra justificação. Complementa essas ações com as de informar dando indicação à aluna da validade da conclusão apresentada (L.6 e L.9), com vista a valorizar a sua estratégia e a transmitir confiança para continuar a avançar com outras hipóteses explicativas para o raciocínio em análise. A insistência do professor leva os alunos a encontrarem outras razões para a não validade do segundo passo, através da comparação e avaliação do raciocínio apresentado com os dados presentes no enunciado:

[L.10] Aluno: Não, é porque 5 mais 15 mais 7 e meio dá 27 e meio e não vai dar 30.

$P$ : A conclusão do grupo é importante. Aquele terceiro passo é importante, porque perceberam que a Sandra tinha que ter sempre um número par de votos, porquê? Porque o Lucas ia ter metade da Sandra. Agora, por que é que aquele segundo passo está mal? Eu sei o que é que vocês raciocinaram mas se calhar não raciocinaram muito bem. Esse

[L.15] 5 e aquele 15. Vocês começaram com 10, depois viram que o 10 não dava.

(Aula Equações, janeiro de 2014).

Através das ações de desafiar, concretizadas na análise de um raciocínio, o professor consegue que os alunos apresentem outras razões que melhorem a resolução exposta (L.10). O professor continua a reforçar a importância da estratégia partilhada, valorizando as conclusões estabelecidas e oferecendo uma interpretação para a justificação apresentada, de acordo com os dados do enunciado, através das ações de informar (L.12-13). O professor desafia os alunos a pensarem novamente no segundo passo, por ainda não terem oferecido todas as justificações válidas para a sua incorreção em termos do rigor da escrita - ações de desafiar. Contudo, perante a dificuldade dos alunos em apresentar a justificação, recorre às ações de apoiar para focar mais a sua atenção, levando-os a pensar sobre os votos específicos da Francisca e da Sandra, como exibe o segmento de discussão abaixo:

P: Qual era a relação entre os votos da Sandra e da Francisca?

Mafalda: 5 votos de diferença.

$P$ : Então e quantos estão ali no quadro?

Aluno: 10. (impercetível) 
[L.20] P: Deixa ficar o 7 e meio, não há problema nenhum. Assim, já está mais de acordo, apesar de que não são 30 votos. Pronto, mas o que o grupo pensou foi: bem, pelo menos eu já sei que a Sandra nunca pode ter um número impar de votos, portanto e já restringiu nos 30 votos, deitou logo ali uma série de votos fora, tornou mais fácil a conclusão e depois fizeram por tentativas, não foi? Vocês fizeram por tentativas.

(Aula Equações, janeiro de 2014).

Essa opção conduz os alunos à conclusão pretendida e à apresentação de várias justificações para o raciocínio presente no segundo passo. Recorre às ações de apoiar para filtrar os contributos mais importantes da estratégia apresentada pelo grupo (L.21-24) e que decorrem do encaminhamento que deu à apresentação e justificação dessa estratégia pelos alunos.

Com as ações empreendidas, o professor pretende alertar os alunos para o rigor da escrita matemática, principalmente quando deseja ser autossuficiente na mensagem a passar, embora os alunos tenham como objetivo apresentar somente uma tentativa que desencadeia a sua estratégia de resolução. O professor mobiliza o seu conhecimento didático, especialmente nas vertentes do conhecimento da Matemática e da prática letiva para mostrar aos alunos os aspectos que precisam ser clarificados ou corrigidos numa resolução: "Permitem pelo menos junto dos alunos perceber por que é que erraram, ou por que é que este caminho é o melhor, ou por que é que este é o pior. E isso é possivel ser feito com a discussão e se houver confronto de ideias e de resoluções" (EF, junho de 2014).

De fato, a turma, ao oferecer diversas justificações para as mesmas ideias, evidencia a sua incompletude e a necessidade de ser reescrita de forma a satisfazer todas as condições necessárias. Durante esse trajeto, o professor também tem o cuidado de destacar os aspectos mais relevantes da resolução em análise (L.12-13 e L.21-24), mostrando aos alunos que a sua estratégia é válida e importante (L.6 e L.11).

Jorge considera a síntese das principais ideias como um elemento importante para o envolvimento dos alunos na discussão coletiva - conhecimento da prática letiva - antes de avançar para a apresentação de outras estratégias de resolução. O professor promove a discussão a partir da escolha cuidada de um grupo para apresentar a sua estratégia de resolução e continua solicitando contributos, focados, neste caso, na análise de um certo passo da resolução. Essa prática evidencia as aprendizagens realizadas com a sua participação neste projeto, na medida em que, em situações anteriores, a discussão não era preparada previamente e decorria em função das ideias que iam sendo apresentadas pelos alunos: "Em função das respostas que me vão dando então assim crio essa discussão ou não" (EI, setembro de 2013). 
Pelo conhecimento da prática letiva, o discurso instrutivo do professor mostra que, numa primeira fase, pretende ter muitas ideias para serem discutidas a partir da apresentação da estratégia de resolução de um grupo - solicitação e discussão de muitas ideias - não se preocupando, assim, com o conteúdo das mesmas - conteúdo matemático não filtrado. Contudo, logo a seguir foca a atenção dos alunos num passo da resolução (L.3-4) e, mais tarde, oferece um raciocínio para analisarem (L.16) - filtragem - que conduz à solicitação e discussão de mais ideias.

Nesse momento, o professor tem propósitos explícitos para debater certos raciocínios, com o objetivo de alertar para o rigor da escrita matemática - conteúdo matemático filtrado. $\mathrm{O}$ professor recorre às ações de informar para continuar a promover a apresentação das estratégias, alertando os alunos para a introdução de uma estratégia que envolve linguagem matemática formal com recurso explícito a conceitos e procedimentos matemáticos:

[L.25] P: Vou pedir rapidamente a este grupo (...) Para perceberem que a abordagem mesmo sendo feita com equações, nem sempre pode ser igual em todos os grupos. Certo? (A aluna passa a resolução no quadro) (...) Qual foi a diferença entre a resolução daquele grupo para este grupo?

Filipa: Nós aqui pusemos o x na Francisca e eles puseram na Sandra.

[L.30] P: Obviamente que se a minha incógnita, o meu x é posto numa pessoa diferente, todos os outros também alteram. Ou seja, enquanto aqui o x vai representar os votos da Sandra, ali foi os da Francisca. Claro que os da Sandra tem mais, vai ser. Vai ser que expressão? Já não é $x$ menos 5 mas sim $x$ mais 5 . E o Lucas vai ter metade de qual? Vai ser metade daquele valor. (...) Então e será que havia possibilidades de fazer uma

[L.35] equação daquelas sem denominadores?

(Aula Equações, janeiro de 2014).

O professor, com o objetivo de levar os alunos a comparar as duas estratégias de resolução (já tinha sido apresentada outra envolvendo a escrita de uma equação), alerta-os para a existência de uma outra estratégia que, embora recorrendo à escrita de uma equação, é distinta da já apresentada (L.25-26) - ações de informar. Pretende, com isso, despertar o interesse dos alunos para analisar e compreender as diferenças presentes nas duas estratégias. Através das ações de desafiar, incentiva a aluna a explicar a sua estratégia de resolução, mas rapidamente pega na sua fala e conclui todas as explicações e comparações que deviam ter sido apresentadas pela aluna (L.30-34). Jorge reconhece que, por vezes, se deixa entusiasmar e envolver na partilha e negociação de ideias e acaba por ultrapassar os alunos, mesmo sem ser essa a sua intenção: "Quando dá conta já está a ultrapassar o aluno, eu isso reconheço que é um defeito que, às vezes, pelo menos eu tenho, não nego" (EF, junho 2014).

Neste caso, a sua intenção passa por desafiar os alunos a pensarem sobre uma outra estratégia que traz novidades às já apresentadas - escrita de uma equação não envolvendo o uso de denominadores como as anteriores (L.34-35) - ações de desafiar. Jorge associa esse 
fenômeno às expectativas que tem para cada aula e, em particular, para a discussão coletiva: "Porque uma pessoa tem uma expectativa quando vai para uma aula (...)" (EI, setembro de 2013). A provocação lançada por Jorge é acolhida pelos alunos e a estratégia que quer fazer emergir aparece, como mostra o segmento seguinte:

P: Diz lá Tomás. Deixem dizer o Tomás. Diz.

Tomás: $O$ do Lucas é X.

$P$ : Vamos pôr aí o x a dizer. Se o do Lucas for o x. Só quero que me ponhas aí a equação. Se o Lucas for $o x$.

[L.40] Tomás: A Sandra fica $2 x$. (...) E a Francisca fica com $2 x$ menos 5.

$P$ : A Sandra fica com o dobro. E a Francisca fica com menos 5 que a Sandra.

Tomás: $2 x$ menos 5 .

P: Reparem que não tem denominadores. Portanto, reparem: apesar de ser com equações tenho resoluções diferentes. Às vezes até consigo escolher o que é mais fácil. Enquanto

[L.45] aqui vocês têm que trabalhar com denominadores, ali ficou sem denominadores. (Aula Equações, janeiro de 2014).

O professor recorre às ações de apoiar para acompanhar a exposição e negociação de ideias do aluno (L.41) e às de desafiar (L.38-39) para o incentivar a exprimir, antes de escrever a equação, uma relação matemática que traduza o número de votos de cada um dos intervenientes da tarefa. Essa opção favorece uma melhor compreensão dos monômios envolvidos na equação pelo restante dos alunos da turma e que não pensaram nessa estratégia. A discussão da tarefa termina com a conclusão das principais ideias expostas pelos alunos, em que o professor reforça a importância de conseguirem escrever equações diferentes para a mesma informação apresentada em linguagem natural e a vantagem de mobilizarem conceitos matemáticos ligeiramente diferentes com graus de dificuldades também distintos, apoiando-se nas ações de informar.

O discurso instrutivo do professor denota a sua preocupação inicial em solicitar $e$ discutir muitas ideias com o convite à apresentação e explicação das estratégias de resolução usadas pelos alunos para, em seguida, focar a sua atenção na existência de um conceito matemático mais potente que não trabalha com casos particulares (equação) - filtragem das ideias partilhadas - que serve de alavanca à solicitação e discussão de mais ideias, através do convite à escrita de uma equação sem denominadores e termina com uma breve conclusão da sua parte.

O professor, ao querer fazer surgir a escrita de três equações diferentes para a tradução da mesma informação em linguagem verbal, mobiliza o seu conhecimento da prática letiva em articulação com o da aprendizagem e dos alunos, para alertar os alunos para as diversas interpretações que podem ser feitas da mesma informação e as respectivas consequências em termos de procedimentos matemáticos que envolvem: "É importante que as pessoas percebam 
que há maneiras diferentes de pensar e verem no confronto que chegam ao mesmo resultado pensando por maneiras diferentes (...) os alunos defendem a sua dama e gostam de confrontar as suas ideias" (EF, junho de 2014). Pretende, ainda, que os alunos argumentem sobre as suas ideias, defendendo o seu processo de resolução.

\section{0 caso de Afonso}

\subsection{0 professor}

Afonso tinha, no momento do estudo, 25 anos de serviço e leciona aos 7. ${ }^{\circ}$ e $8 .^{\circ}$ anos de escolaridade. Apesar de não costumar frequentar encontros de professores de Matemática nem participar em projetos, decidiu participar no PPDMEA, porque reconhece que ele pode contribuir para o seu enriquecimento: "Estou sempre predisposto a aprender alguma coisa, há sempre coisas que nós podemos ganhar" (EI, setembro de 2013). Em particular, identifica no tema discussões matemáticas potencialidades instrutivas, por permitirem aos alunos realizarem aprendizagens significativas: “Da discussão de ideias (...) surgem aprendizagens que de outra forma (...) levam muito mais tempo e (...) os miúdos chegarem às suas próprias conceções, (...) tem uma aprendizagem completamente diferente, muito mais consolidada" (EI, setembro de 2013).

A Álgebra é um tema que lhe desperta interesse, por reconhecer que levanta grandes dificuldades aos alunos, fundamentalmente na simbologia que mobiliza: "A Álgebra é um dos temas onde os alunos revelam muitas dificuldades (...) abstrato e, por vezes, difícil de entender (...) É esta vontade em combater estes aspectos inibidores da aprendizagem que procuro experimentar novas situações, usando metodologias variadas" (RI, julho de 2014).

$\mathrm{O}$ professor salienta que as aprendizagens realizadas no PPDMEA, em especial as relacionadas com a preparação da discussão coletiva, permitir-lhe lidar com mais segurança com situações imprevistas em sala de aula: "Acho que temos a ganhar ainda o facto de planificarmos, tu estás em vantagem na forma como podemos conduzir a discussão, (...) claro que não vamos prevê-las todas, mas se calhar ajuda-nos de alguma forma a não nos apanhar tão desprevenidos" (2. ${ }^{a} \mathrm{SC}$, outubro de 2013).

Embora reconhecendo que nem tudo pode ser antecipado, admite a notoriedade desse trabalho ao pensar em diversas abordagens que contribuem para uma avaliação mais eficaz da exequibilidade de certa estratégia e a importância de ser partilhada em coletivo. Vê na sua participação no projeto uma forma de desenvolver a sua prática letiva, através da produção de 
materiais para as suas aulas e da partilha de experiências resultantes da exploração desses materiais.

\subsection{A condução da discussão}

Afonso inicia a discussão coletiva com a apresentação das estratégias de resolução desenvolvidas pelos alunos, convidando à explicação do raciocínio seguido - ações de elicitar e desafiar. O primeiro grupo que o professor seleciona para iniciar a apresentação envolve linguagem matemática informal, processo por tentativa organizado numa tabela:

P: Mas explica aos teus colegas como é que pensaram.

Aluna: Eu baseei-me na Francisca, pois é a partir dela que conseguimos saber o da Sandra.

P: Mas essa tabela como é que surgiu? (...) Foi experimentar, não? (...) Foste por

[L.50] tentativas? (...) Começaste ali pela Sandra, tens ali 10, depois a Francisca 5, 5. Mas o total é 20. E a turma tinha 30 alunos.

Aluna: Depois experimentei a Francisca com 9 que depois dava 7 e a Sandra ficava com 14. $O$ Lucas ficava com 7. Depois deu o resultado de 30.

P: Mas tu foste ajustando os valores de modo a que tivesses aí um total de 30.

(Aula Equações, janeiro de 2014).

Afonso inicia a apresentação com o convite implícito à exibição da estratégia seguida, optando por acompanhar explicitamente esse convite do pedido de explicação do raciocínio desenvolvido (L.46). As ações de elicitar empreendidas pelo professor no início da discussão desta tarefa surgem combinadas com as de desafiar. Durante a apresentação da aluna, o professor presta-lhe um apoio muito próximo, levando-a a clarificar o raciocínio seguido na sua resolução (L.49-51; 54) - ações de apoiar. Contudo, dá-lhe pouca liberdade de expressão, oferecendo algumas justificações que deviam ser apresentadas pela aluna, nomeadamente a razão para ter abandonado a primeira tentativa (L.51). É também o professor que menciona o tipo de estratégia seguida pelo grupo (L.49-50). O professor reconhece que é difícil articular a sua intervenção com a dos alunos: "Há sempre uma tendência de falar, eu falo por mim (...) volta meia volta, aquilo acho que é um bocadinho mais forte que eu" (4. ${ }^{\text {a }} \mathrm{SC}$, janeiro de 2014). A vontade que tem em levar os alunos a clarificar as suas ideias e a atingir o pretendido, condicionam, por vezes, a sua prática e originam situações em que a sua intervenção se sobrepõe à dos alunos: “O professor serve ali como um mediador e encaminha as coisas por onde quer, não é? Pronto. E ajuda-os no sentido de clarificar" (EI, setembro de 2013).

Durante o acompanhamento à apresentação da aluna, Afonso filtra as ideias mais importantes, de modo a ficarem acessíveis a todos. Com a sua última intervenção, reforça a razão para se ter abandonado a primeira tentativa e alerta para a verificação das condições presentes no enunciado da tarefa (L.54). O professor aproveita o fato de o grupo que está a 
apresentar ter resolvido a tarefa através de duas estratégias diferentes para promover a comparação e avaliação de estratégias, desafiando a aluna a relacionar as duas resoluções:

[L.55] P: Então e depois como é que surgiu a outra parte?

Aluna: Também baseei-me na Francisca e depois isto corresponde aos da, ox +5 corresponde aos da Sandra.

P: Porque ela dizia que tinha mais 5 votos do que a Francisca, certo?

Aluna: Depois isto eram os da Francisca. (...) E este é os do Lucas, $x$ mais 5 a dividir por

[L.60] 2.

$P:$ E porquê a dividir por 2? (...)

Aluna: Porque era metade dos votos da Sandra.

P: Como a Sandra tinha $x$ mais 5. Portanto, fizeste $x$ mais 5 sobre 2, certo?

Aluna: Depois dava 30 o total.

[L.65] P: Que era o número de alunos da turma.

(Aula Equações, janeiro de 2014).

Com o convite que dirige à aluna, o professor pretende que os alunos comparem e avaliem duas estratégias de resolução distintas, a partir da mesma interpretação da informação dada no enunciado - ações de desafiar. Durante a apresentação da aluna, Afonso, suportado nas ações de apoiar, vai filtrando os contributos mais importantes para que sejam reconhecidos como ideias válidas pelos outros e oferecendo interpretações para os argumentos expostos (L.58; 63; 65) e vai questionando, com vista a avaliar os raciocínios apresentados (L.61) ações de desafiar. Procura que, nessa avaliação, os alunos relacionem a linguagem matemática com as condições do problema. A primeira intervenção do professor tem como propósito solicitar muitas ideias para serem discutidas, mas com o evoluir da apresentação da aluna, Afonso direciona o discurso para determinadas ideias que pretende que sejam clarificadas ou justificadas - filtragem das ideias partilhadas.

Dando continuidade à exposição da estratégia desenvolvida por este grupo, o professor apoia-se nas ações de desafiar para incitar os alunos a relacionarem a solução da equação com a resposta ao problema:

Aluna: Depois fiz o cálculo. (...) E o que me deu foi 9. (...) Que eram os votos que a Francisca recebeu, depois fiz o resto.

P: Como a pergunta era quem ganhou as eleições, não é? Portanto, o que é que foste fazer? (...) A Francisca era 9, que era o que tinha dado, a Sandra. (...) 9 mais 5 porque.

[L.70] Porquê?

Aluna: Era $x$ mais 5.

P: Porque ela tinha recebido mais 5 votos do que a Francisca.

Aluna: Que dava 14, depois o Lucas que era 14 a dividir por 2.

P: Metade dos da Sandra que era 14 a dividir por 2. Certo.

(Aula Equações, janeiro de 2014).

O professor procura que a aluna justifique os raciocínios que apresenta à medida que vai relacionando a resposta ao problema com a solução encontrada para a equação. Em simultâneo, recorre às ações de apoiar para a ajudar a avançar nas suas explicações (L.68-70) 
e para oferecer outras interpretações para os argumentos apresentados, relacionando com as condições do problema (L.72).

O professor apoia-se no seu conhecimento da prática letiva quando leva este grupo de alunos a relacionar as duas resoluções e a interpretar a solução obtida com a resposta ao problema, quando poderia ter introduzido um grupo novo na discussão após a apresentação da primeira estratégia. Com vista à comparação e avaliação de mais estratégias de resolução, o professor introduz um novo grupo na discussão, levando à explicação do seu processo de resolução:

[L.75] P: Talvez, este grupo que fez uma maneira um bocadinho diferente. (...)

Aluna: Nós escolhemos a Sandra, em que x era o número de votos da Sandra.

$P: x$. A vossa colega anterior considerou o x como sendo o número de votos da Francisca, este grupo considerou o $x$ o número de votos da Sandra, portanto o resultado vai ter que dar diferente, certo? (...)

[L.80] Aluna: O x menos 5 é os votos da Francisca, porque dizia que a Francisca tinha menos 5 votos que a Sandra, ou que a Sandra tinha mais 5 votos que a Francisca.(...) Depois fizemos mais um meio de $x$, porque o Lucas tinha um meio dos votos da Sandra. (...) Fizemos mais $x$ que é o número de votos que a Sandra tem.

P: Da Sandra. Ok. Sim?

[L.85] Aluna: 30 que é o número total de votos.

(Aula Equações, janeiro de 2014).

Para despertar o interesse dos alunos para a análise de um outro processo de resolução e comparação com o seu ou os já apresentados, o professor, apoiado nas ações de informar, começa por dar a indicação que vai ser apresentado um processo distinto, sem explicitar essa diferença (L.75). Para focar a atenção dos alunos no aspecto da resolução que a distingue das anteriores, Afonso, através das ações de apoiar, compara as designações das incógnitas (L.7778) e lança um novo convite que pretende voltar a chamar os alunos para a partilha de ideias, já que se podiam dispersar em virtude da conclusão que apresenta. Assim, apoiado nas ações de desafiar, incita os alunos a pensar sobre o resultado da equação (L.78-79).

Com essa ação, o professor pretende negociar com os alunos um procedimento particular: conjunto solução diferente em virtude da escrita de uma equação também diferente. Durante a comunicação da aluna, recorre às ações de apoiar para manifestar concordância com as justificações que vão sendo apresentadas, já que revelam um rigor e aprofundamento razoáveis - avaliação - transmitindo-lhe confiança para progredir na sua explicação. $\mathrm{O}$ professor usa a conclusão da discussão para reforçar a possibilidade de abordagens diversificadas para a resolução de um mesmo problema, como mostra o excerto seguinte:

Investigadora: Reparem que obtiveram 3 equações diferentes. Esta última não tinha denominadores, enquanto as anteriores tinham.

Professor: Exatamente. (...) Mais simples.

Investigadora: Dependendo do que escolhiam. 
(Aula Equações, janeiro de 2014).

Através das ações de informar, os alunos são alertados para a existência de diversas formas de se resolver um problema, destacando as circunstâncias em que isso acontece designação da incógnita. Afonso considera esse aspeto fundamental nas discussões que envolvem o trabalho com equações: "Na discussão em grande grupo, chamar-lhes atenção para as diferenças que havia, em que apesar de muitas vezes o $x$ ser diferente, dar um valor diferente, porque lhes atribuíram outra designação, vamos ver que depois no fim (...) a resposta era a mesma" (EF, junho de 2014).

O professor valoriza bastante a possibilidade de os alunos apresentarem e explicarem diferentes tipos de estratégias e relacionarem com a resposta ao problema. Com esse alerta, reforça a relação entre a solução de uma equação e a resposta ao problema, em função da definição da incógnita. A conclusão da discussão que o professor promove revela que a sua atuação é suportada pelo seu conhecimento da prática letiva em articulação com o da aprendizagem e dos alunos.

\section{Conclusão}

Os professores estudados, apoiados no seu conhecimento didático, empreendem diversas ações de ensino na condução da discussão coletiva, que organizam em três momentos principais: apresentação; comparação, avaliação e filtragem; e conclusão (Figura 4).

Dando início à discussão, para apresentação e explicação das estratégias desenvolvidas, os professores recorrem a ações de elicitar combinadas com ações de desafiar com o convite a alunos específicos, iniciando por resoluções que usam linguagem matemática informal. Enquanto Jorge usa ações de desafiar para levar os alunos a analisar um certo passo da resolução que inclui um raciocínio errado que precisa ser corrigido, Afonso apoia-se nessas ações para fomentar a justificação de raciocínios.

Para promover a comparação, avaliação e filtragem, os professores recorrem a ações de apoiar, informar e desafiar. Usam as ações de apoiar para focar aspectos determinantes das resoluções apresentadas e filtrar contributos importantes, tal como em Cengiz, Kline e Grant (2011), e acompanhar a exposição e negociação de ideias. Afonso apoia-se, ainda, nestas ações para oferecer interpretações para as ideias que estão a ser apresentadas. Ações de informar são usadas pelos professores para despertar o interesse para a análise de estratégias de resolução diferentes das apresentadas. Jorge usa, ainda, estas ações para oferecer interpretações para 
raciocínios expostos pelos alunos. Os professores apoiam-se em ações de desafiar para levarem os alunos a compararem estratégias distintas e negociarem procedimentos e justificar raciocínios. Jorge usa, também, estas ações para levar os alunos a apresentarem diversas razões para a não validade de um raciocínio exposto e para introduzir representações.

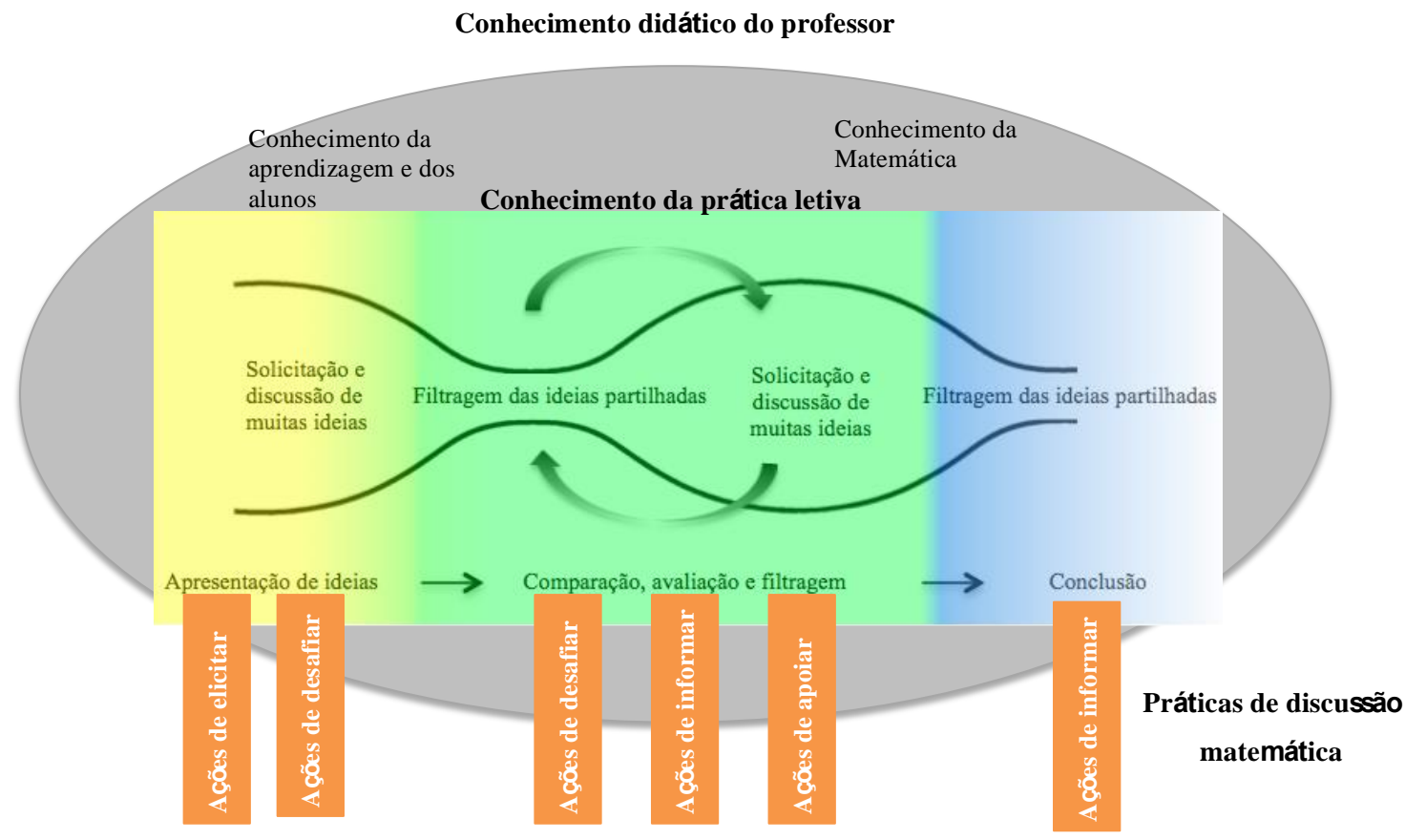

Figura 4 - Conhecimento e práticas de discussão matemática Fonte: Dados da pesquisa (2017).

Na conclusão da discussão, Afonso usa sobretudo ações de informar para reforçar a possibilidade de diferentes abordagens para um dado problema e apresentar razões para essa diferença. Pelo seu lado, Jorge usa essas ações para fazer uma breve síntese das principais ideias discutidas com a tarefa, em contraste com o estudo relatado em Ponte, Mata-Pereira e Quaresma (2013), em que estas ações estavam, frequentemente associadas ao final da resolução de cada alínea. Durante a discussão das tarefas, os professores sentiram, por vezes, dificuldade em articular a sua fala com a dos alunos, acabando por apresentar justificações que poderiam ter sido dadas por estes. Justificam-no pela vontade de atingir o propósito da aula (no caso de Afonso) ou de levar os alunos a apresentar várias justificações para a incorreção de um certo raciocínio (no caso de Jorge).

O modo como os professores conduzem a discussão e os aspectos que mais valorizam nessa condução são influenciados pelo seu percurso profissional: Jorge costuma participar em projetos curriculares e de investigação e é formador na especialidade do uso de tecnologia na sala de aula; Afonso é a primeira vez que participa num projeto deste tipo e não costuma frequentar encontros relacionados com a Didática da Matemática. Assim, é natural que Jorge 
esteja mais sensível aos aspectos a valorizar na condução de uma discussão do que Afonso, que realiza no momento do estudo aprendizagens significativas relativas a esta questão.

Por isso, Jorge parece preocupar-se bastante com o conteúdo da discussão dando logo de início indicação ao aluno que está a apresentar o que pretende que seja exposto no quadro, com vista à discussão de um certo passo da resolução que verificou estar incorreto, analisando as razões da incorreção. Além disso, desafia os alunos a pensarem sobre uma estratégia que não emergiu nas suas resoluções e, na conclusão, procura fazer uma breve síntese das principais ideias discutidas. Afonso parece mostrar uma maior preocupação com a forma de conduzir a discussão, fazendo aparecer várias estratégias de resolução para analisar em coletivo, destacando na conclusão que um mesmo problema pode ser resolvido de diversas formas.

Jorge mobiliza o seu conhecimento da Matemática em articulação com o conhecimento da prática letiva para evidenciar o que precisa ser clarificado numa resolução e na síntese das principais ideias. Já Afonso fá-lo para relacionar resoluções e interpretar as soluções obtidas. O conhecimento da prática letiva em articulação com o conhecimento da aprendizagem e dos alunos é usado pelos professores para alertar os alunos para as diversas interpretações que se podem fazer a partir da tradução de uma dada informação de linguagem verbal para Matemática e respectivas implicações em termos de procedimentos. Jorge mobiliza o seu conhecimento da prática letiva, por exemplo, quando opta por continuar a incentivar os alunos a argumentarem sobre a incorreção de um certo raciocínio quando podia ter introduzido outro grupo na discussão e Afonso quando leva um grupo de alunos a relacionar duas resoluções distintas apresentadas na sua folha de resposta e a relacionar a solução da equação com a resposta ao problema.

Em síntese, este estudo mostra que é importante estudar as práticas de discussão matemática com o objetivo de as compreender melhor e proporcionar momentos produtivos de aprendizagem aos alunos, já que é fundamental que o professor consiga decidir quando deve continuar a discussão de uma ideia ou parar para pedir clarificações e usar ideias dos alunos para fazer observações matemáticas.

\section{Referências}

BALL, D. L.; THAMES, M. H.; PHELPS, G. Content knowledge for teaching: What makes it special? Journal of Teacher Education, Washington, v. 59, n. 5, p. 389-407, nov./dez. 2008.

BOGDAN, R.; BIKLEN, S. Investigação qualitativa em educação: Uma introdução à teoria e aos métodos. Porto: Porto Editora, 1994.

CENGIZ, N.; KLINE, K.; GRANT, T. J. Extending students' mathematical thinking during wholegroup discussions. Journal of Mathematics Teacher Education, Dordrecht, n. 14, p. 355-374, 2011. 
ERICKSON, F. Qualitative methods in research on teaching. In: M. WITTROCK (Ed.). Handbook of research on teaching. New York: Macmillan, 1986. p. 119-161.

HARGREAVES, A. Os professores em tempos de mudança: O trabalho e a cultura dos professores na idade pós-moderna. Lisboa: Mc Graw-Hill, 1998.

PONTE, J. P. Estudos de caso em educação matemática. Bolema, Rio Claro, n. 25, p. 55-81, 2006.

PONTE, J. P. Estudando o conhecimento e o desenvolvimento profissional do professor de matemática. In: N. PLANAS (Ed.). Educación matematics: Teoría, critica y prática. Barcelona: Graó, 2011. p. 83-98.

PONTE, J. P.; MATA-PEREIRA, J.; QUARESMA, M. Ações do professor na condução de discussões matemáticas. Quadrante, Lisboa, v. 22, n. 2, p. 55-81, 2013.

SHERIN, M. G. A balancing act: developing a discourse community in a mathematics classroom. Journal of Mathematics Teacher Education, Dordrecht, n. 5, p. 205-233, 2002.

SHULMAN, L. S. Knowledge and teaching: Foundations of the new reform. Harvard Educational Review, Cambridge, v. 57, n. 1, p. 1-22, fev. 1987.

SHULMAN, L. S. Those who understand: Knowledge growth in teaching. Educational Researcher, Washington, v. 5, n. 2, p. 4-14, fev. 1986.

STEIN, M. K. et al. Orchestrating productive mathematical discussions: five practices for helping teachers move beyond show and tell. Mathematical Thinking and Learning, Abingdon, n. 10, p. 313 $-340,2008$.

Submetido em 09 de Agosto de 2017. Aprovado em 10 de Janeiro de 2018. 